\title{
A experiência de afastamento do trabalho por adoecimento vivenciada como processo de ruptura ou continuidade nos modos de viver
}

\author{
Márcia Ziebell Ramos ${ }^{1}$, Jaqueline Tittoni ${ }^{2}$ e Henrique Caetano Nardi ${ }^{3}$ \\ Departamento de Psicologia Social e Institucional \\ Universidade Federal do Rio Grande do Sul
}

\begin{abstract}
O presente estudo problematiza os processos de subjetivação a partir da experiência de afastamento do trabalho por adoecimento em trabalhadores de um hospital público de Porto Alegre (RS). Discutem-se as experiências desses trabalhadores que se encontram no período de reintegração ao trabalho com o objetivo de analisar os processos de ruptura/continuidade produzidos nessas situações. Do ponto de vista conceitual, tomamos a noção de acontecimento-ruptura como operador analítico para compreender os efeitos do afastamento nos processos de subjetivação desses trabalhadores. Através deste estudo, pode-se perceber que, nas diferentes situações, esboça-se uma identidade de "trabalhador sem trabalho" que pressiona para a reconfiguração dos modos de viver e dos projetos de vida dos trabalhadores.
\end{abstract}

Palavras-chave: Trabalho, Subjetividade, Reabilitação profissional, Saúde do trabalhador.

The experience of being away from work due to work related diseases lived as rupture or continuity process of ways of living

This study problematizes the subjectification processes associated to the experience of being away from work due to work related diseases among workers from a Porto Alegre's public hospital. We will discuss the experiences of workers in the period of occupational reintegration in order to analyze the rupture or continuity processes present in these situations. We chose the concept of rupture-event as an analytical operator aiming to understand the effects of being away work from in the subjectification processes. Immediately, we notice that, in different situations, the emergence of a "worker without work" identity that reconfigures the workers' way of life and life projects.

Keywords: Work, Subjectivity, Professional rehabilitation, Worker's health.

\section{Introdução}

\begin{abstract}
A discussão contemporânea sobre o trabalho está perpassada pela temática da - inclusão/exclusão social, ou desfiliação como prefere Robert Castel (1998), uma vez que o trabalho continua a ser uma forma central de inscrição social. Assim, analisar o trabalho é, ainda, uma importante forma de compreensão da vida social e da organização da sociedade. A análise do trabalho mostra que as noções de produtividade e de capacitação dos trabalhadores ainda figuram como elementos centrais, de modo que o trabalhador está em constante pressão em termos de exigências de qualificação e de atualização para o desempenho do trabalho como forma de garantia do aumento da produtividade. As temáticas do adoecimento no trabalho e da reabilitação profissional colocam em questão as exigências de produtividade e de capacitação, uma vez que estão relacionadas às limitações impostas aos trabalhadores.
\end{abstract}

\footnotetext{
1 Mestre em psicologia social e institucional.

2 Professora do Departamento de Psicologia Social e Institucional.

3 Professor do Departamento de Psicologia Social e Institucional.
} 
Este estudo enfoca as experiências dos trabalhadores em processo de reabilitação profissional e discute as próprias práticas de reabilitação profissional. Estas podem vir a constituírem-se em mais um espaço de reprodução das estratégias de dominação que marcam o discurso da incapacidade e da quase "inutilidade" daqueles trabalhadores que não conseguem acompanhar as exigências do trabalho ou, ainda, buscar outras alternativas de trabalho que possam apontar para outras potencialidades produtivas como trabalhadores.

Este estudo foi realizado junto a trabalhadores de um hospital público e universitário de Porto Alegre (RS) em processo de reabilitação profissional e problematiza os processos de subjetivação a partir da experiência de afastamento do trabalho por adoecimento. As experiências desses trabalhadores serão discutidas com o objetivo de analisar os processos de ruptura/continuidade produzidos nessas situações. Para esta análise tomamos a noção de acontecimento-ruptura (Carreteiro, 2003) como operador analítico para compreender os efeitos do afastamento nos processos de subjetivação dos trabalhadores. Nas diferentes experiências de ruptura/continuidade em situações de adoecimento, de imediato percebe-se que se esboça uma identidade de "trabalhador sem trabalho", que pressiona para a reconfiguração dos modos de viver e dos projetos de vida dos trabalhadores. Essa experiência convoca o trabalhador desde um lugar de "não trabalho", no qual, ao considerar a importância que o trabalho possui enquanto referência na vida social, os processos de subjetivação estão marcados pela incapacidade, inutilidade e pelo sofrimento.

\section{Sobre trabalho e processos de subjetivação}

O trabalho pode ser pensado como um campo de lutas no qual a legitimidade do saber mostra-se como importante ponto de referência e a questão do poder é um tema central. Nesse sentido, o trabalho pode ser entendido como campo de relações que produz verdades sobre o que é o trabalho, o que é ser trabalhador e sobre os modos de trabalhar e de viver. Como campo de lutas que implica saberes e verdades, o trabalho compreende processos de exploração e de dominação, assim como processos de resistência e de criação (Foucault, 1995). A relação entre subjetividade e trabalho delineia-se a partir de pontos de fixação e deslocamento do poder que evidenciam os espaços de reprodução e ruptura produzidos nos contextos de trabalho.

Tomamos aqui, conforme Tittoni (2008), a definição de trabalho "como um conjunto de infinitas possibilidades de articulação das fontes naturais e sociais que possibilitam a utilização da possibilidade criativa humana para a produção da vida (criação) e de sua manutenção (sobrevivência)".

O trabalho, como sujeição, pressiona para modos de inscrição nas relações sociais que devem garantir um lugar legitimado socialmente, no caso, o lugar de trabalhador formal. Estar "sujeito" ao trabalho é, também, estar "sujeito" a um modelo de trabalhador e reconhecer-se nele. Modelo esse geralmente associado ao emprego e ao salário e pautado a partir das configurações propostas pela ordem capitalista. Se tomarmos esse "modelo" de trabalhador desde a lógica do trabalho capitalista, podemos pensar que ele pode apontar para relações marcadas pela reificação do vínculo empregatício, no qual o trabalhador pode produzir-se a si mesmo como uma mercadoria.

Foucault (1995) afirma que as relações de poder geram tensionamentos e resistências, provocando "um 'agonismo', mais do que um 'antagonismo' essencial, em uma relação que é, ao mesmo tempo, de incitação recíproca e de luta; trata-se, portanto, menos de uma oposição de termos que se bloqueiam mutuamente do que de uma provocação permanente" (p. 245). Ao considerarmos que o sujeito se produz nessa "agonística" (Foucault, 1995), podemos pensar que 
os sujeitos se reconhecem nos contextos de trabalho na complexidade das tramas da resistências e do poder. Essas tramas podem enfatizar aspectos de sujeição ou de criação, ou seja, o trabalhador "modela-se" na ordem capitalista ou busca, nesta ordem, fluxos de criação e de resistência. As configurações das relações de poder no trabalho evidenciam as condições de possibilidade de emergência de determinadas verdades sobre o trabalho e sobre os trabalhadores.

Para a análise dos modos como o sujeito se reconhece nos jogos de verdade que configuram o trabalho, tomamos como central a noção de modos de subjetivação enfocando as formas "como o sujeito faz a experiência de si nos jogos de verdade" (Foucault, 1999, p. 25). Os jogos de verdade produzidos e reproduzidos no trabalho delineiam, assim, as experiências e as formas de auto-reconhecimento do trabalhador.

Cabe ressaltar que, como os processos de subjetivação estabelecem-se a partir de um campo de lutas, podemos pensar que a experiência do sujeito é um aspecto fundamental. Sobretudo, se considerarmos que nos jogos de poder e verdade do trabalho ela é vivida sob condições e possibilidades que podem (re)definir a própria condição de trabalhador. Conforme Ortega (1999), "a experiência constitui uma práxis espiritual ou ascética, ou seja, as transformações que deve experimentar o sujeito para alcançar outra forma de ser" (p. 43). Esse processo não só explicita os jogos de poder, mas os organiza para produzir "outras formas de ser" e, assim, trata-se de uma experiência que pode implicar novos "desejos", devires ou alteridades.

O trabalho pelo seu "avesso", o "não-trabalho", convoca-nos a entrarmos nos domínios do risco da desfiliação, por um lado, e da resistência, por outro. A desfiliação é aqui entendida no sentido proposto por Castel (1988), a saber, como processo crescente de fragilização e ruptura dos laços e das relações sociais conquistadas no trabalho que servem de suportes no cotidiano.

Com relação ao afastamento do trabalho, pode-se pensar nas marcas e nos efeitos da lógica da produtividade exacerbada, designando os trabalhadores afastados como incapazes e, necessariamente, como improdutivos. O espaço que ocupam no âmbito das "práticas divisórias" (Foucault, 1995) localiza-os no avesso da norma, fixando-os em uma posição de párias em uma sociedade que reverencia o trabalho enquanto única forma de inscrição social e modo de vida considerado normal e digno. Esses sujeitos estão do "outro" lado, fora dos locais de trabalho, muitas vezes presos às amarras dos "sem lugar", sendo constantemente questionados e convocados pela sua incapacidade e improdutividade pelos médicos peritos ou pelos recrutadores e selecionadores, que se pautam pela ordem da produtividade e da velocidade contemporâneas.

O capitalismo contemporâneo faz emergir nesse não-lugar a desfiliação tão bem descrita por Castel (1988) como marca da "nova" questão social. Assim, o afastamento do trabalho acaba por forjar trabalhadores que se subjetivaram através de alguns padrões e estilos que não podem mais manter, produzindo acontecimentos-rupturas importantes nos seus modos de viver e de trabalhar.

Para Carreteiro (2003), "o acontecimento que causa impacto na existência traz em si uma potência disruptiva" (p. 268). Ao romper com a idéia ilusória de linearidade, separa o tempo entre o antes e o depois do acontecimento. Essa ruptura implica na necessidade de buscar outros sentidos, pois "o sujeito não consegue mais se representar como antes" (p. 269).

A ruptura se estabelece no temor de que se desestruture a vinculação ao emprego, ao salário e a garantia dos direitos sociais, tal como previstos na relação contratual marcada pelo assalariamento, que garante relativa proteção e um lugar reconhecido socialmente (Nardi, 2003).

O emprego, assim, pode funcionar como "suporte", possibilitando o acesso ao consumo, às condições de subsistência e à proteção da legislação trabalhista. Carreteiro (2003), a partir 
das idéias de Bourdieu, entende os suportes como "as condições de possibilidade presentes na realidade objetiva, a partir das quais o indivíduo pode estabelecer estratégias na condução de sua vida" (p. 279).

A condição de trabalhador, como lembra Castel (1998), é um ponto de referência na sociedade capitalista, apesar das intensas transformações pelas quais esta tem passado. Mesmo que o trabalho desloque-se da fábrica para a rua, da empresa para o auxílio-doença, mesmo que ocorra o desligamento do emprego, desregulamentando-se e precarizando-se, ele ainda serve como ponto de referência para (re)definir fronteiras e produzir sujeitos, uma vez que continua a ser uma forma central de inscrição social.

Por outro lado, ao pensarmos o afastamento não só como ameaça de desfiliação, podemos apontar sua potencialidade enquanto resistência, uma vez que a condição de "estar fora" pode mobilizar afetos silenciados pelo cotidiano normativo e estafante de trabalho e, então, o trabalhador pode vir a descobrir e descobrir-se em outras habilidades e sensibilidades. Nesse caso, pode reinventar o trabalho de modo a sair da lógica repetitiva da produtividade, potencializando outros fluxos que produzem rupturas nas configurações do trabalho cotidiano, buscando outras atividades e, até mesmo, outros modos de trabalhar. A experiência de si e as formas de reconhecimento e auto-reconhecimento são, então, mobilizadas e movimentadas, definindo e redefinindo processos de subjetivação de modo a expressar os efeitos do trabalho enquanto espaço de produção de valores e verdades sobre o sujeito.

As experiências de criação também estão relacionadas às condições de possibilidade para sua emergência, ou seja, implicam um mínimo de condições em termos de seguridade, de flexibilidade da carreira profissional, entre outros aspectos. Essas condições potencializam a criação e são fundamentais para possibilitar espaços de produção e invenção nos contextos de trabalho.

\section{O adoecimento, o afastamento e a reabilitação como experiências}

Analisaremos o adoecimento relacionado ao trabalho a partir do conceito de saúde proposto por Canguilhem (2002), no qual a saúde configuras-se como "uma margem de tolerância às infidelidades do meio" (p. 159). Ao tensionar a noção de meio e de acontecimento, o autor busca pensar o adoecimento e a saúde como produção de condições de existência e considerando seu caráter de imprevisibilidade. Dessa forma, a presença de uma patologia não estabelece a linha divisória entre o normal e o patológico, mas pode indicar seu devir ou, em outras palavras, os sentidos desse adoecimento e os efeitos produzidos na vida do sujeito.

A experiência de afastamento do trabalho por adoecimento profissional está marcada social e historicamente pela incapacidade para o trabalho e pela insegurança. Essa experiência é intensificada pelo incremento das exigências trazidas pela flexibilização do trabalho, pelo risco do desemprego e pelas dificuldades colocadas na chamada via crucis institucional legal que irá definir a situação do trabalhador afastado frente à busca de "fazer valer" seus direitos. Isso porque, conforme a legislação brasileira, o trabalhador necessita comprovar o vínculo entre o seu adoecimento e o seu trabalho para integrar os benefícios a que tem direito na sua condição. Essa comprovação implica contrapor-se às formas como articulam-se os processos saúde e doença no modo de produção capitalista, na medida em que é mais valorizada a confissão do adoecimento e de seus efeitos do que a busca de formas de superação dessa situação. Ocorre que esses processos se estabelecem no território de poder do discurso médico, em geral, associado ao capital e, dentro do qual, a doença emerge como demonstração de "fraqueza" e 
"incapacidade" do trabalhador, o que faz com que o trabalhador, ao mostrar-se doente, também mostre-se incapaz.

Estudos como os de Barreto (2004), Nardi (1999) e Tittoni (1999) demonstram que esses modos de articulação são marcados pela vergonha do trabalhador, pela sua culpabilização e pela individualização do adoecimento em "casos", de modo a separar as condições e a organização do trabalho da produção da doença.

(...) percebe-se que se instauram outras relações de poder que têm uma origem não exclusiva da relação original do saber médico sobre o corpo do paciente, espacializados no locus privilegiado desta relação que é o hospital, mas sim em outro campo privilegiado que é a disputa entre capital e trabalho intermediado pelo Estado moderno. O corpo em questão é o do "homo faber", o espaço é o da fábrica e a lógica é a da disputa entre capital e trabalho, tendo a burocracia da seguridade social como legitimadora de uma determinada conformação das relações de produção (Tittoni \& Nardi, 1995, p. 162).

Como já anunciamos, este estudo tomou como referência uma pesquisa realizada junto a trabalhadores da saúde territorializados no hospital (Ramos, 2005) ${ }^{4}$, na sua grande maioria, mulheres em situação de afastamento do trabalho por adoecimento. Esses trabalhadores encontravam-se em "benefício", recebendo seus proventos da seguridade social. Suas funções de origem eram diversas: técnico de enfermagem, auxiliar de enfermagem, atendente de alimentação, auxiliar administrativo, auxiliar de limpeza, enfermeira, marceneiro, pedreiro, auxiliar de farmácia, auxiliar de serviços terapêuticos, médico, jardineiro, auxiliar de processamento de roupas, costureira.

A estratégia metodológica escolhida centrou-se na discussão em grupos, pautada pelos pressupostos dos grupos-dispositivos (Barros, 1997, 1994), inscritos na perspectiva da pesquisa intervenção (Rocha \& Aguiar, 2003). A escolha dessa estratégia fundamentou-se no fato de que os grupos-dispositivos priorizam uma abordagem aberta às conexões dos movimentos e devires grupais, buscando-se "a criação de vastas dimensões onde o desejo possa se expressar, se conectar" (Barros, 2007, p. 298). Assim, problematizando os modos de existência, as vivências de ruptura decorrentes do adoecimento, produz-se um questionamento das naturalizações e da sobrecodificação associadas ao lugar de trabalhador doente, procurando-se a promoção das singularizações, através da invenção e da criação.

O grupo de trabalho foi constituído a partir do convite realizado a todos aqueles trabalhadores oficialmente vinculados à equipe do programa de reabilitação do hospital. ${ }^{5}$

Esses trabalhadores estão em diferentes momentos do processo de reabilitação, ou seja: estão aguardando definição de área para estágio, estão em estágio em alguma área na empresa, concluíram estágio e estão aguardando a ocupação de sua vaga definitiva, apresentaram novamente sintomas de suas doenças e estão aguardando os resultados das medidas terapêuticas tomadas por seus médicos ou, nos casos mais graves ou crônicos, estão retornado para o auxílio-doença por não terem bons prognósticos. Mesmo em situações ou momentos diferentes do processo, todos estão envolvidos com a temática da reabilitação profissional.

Desse grupo heterogêneo, no que se refere ao momento do processo de reabilitação em que se encontram seus participantes, foram convidados os 25 trabalhadores vinculados à equipe de reabilitação profissional do hospital para uma reunião de apresentação da proposta da pesquisa. Os convites foram feitos através de contatos telefônicos, realizados pela pesquisadora

\footnotetext{
4 Esta pesquisa foi submetida e aprovada pelo comitê de bioética do hospital em questão.

5 São trabalhadores que já passaram por várias perícias e encaminhados pelo Centro de Reabilitação Profissional (CRP) do INSS para recolocação na empresa, em atividades que atendam às restrições previstas no documento de encaminhamento fornecido pelo técnico do CRP. Esse técnico, chamado de "orientador profissional", avalia as condições de retorno do segurado, para seu posterior encaminhamento à empresa de origem. Nesta, o segurado fará um estágio e, mediante sua conclusão e aprovação, retornará ao quadro funcional da empresa com um Certificado de Reabilitação Profissional, sendo suspenso o seu benefício.
} 
com cada um dos trabalhadores em questão. Compareceram ao encontro 18 dos 25 convidados, sendo que alguns informaram previamente sua ausência. ${ }^{6}$

Na prática, realizaram-se encontros semanais de uma hora e trinta minutos, durante cinco meses, totalizando 20 encontros. Nesse espaço, através da problematização das diversas situações trazidas, buscou-se refletir sobre as diferentes maneiras de experimentar a reabilitação, os modos de vida e de trabalho, os percursos individuais e os sentidos produzidos.

A condução do trabalho grupal buscou criar um espaço para a construção coletiva de conhecimentos e o compartilhamento das experiências de trabalho, das vivências e das trajetórias do adoecimento e da reabilitação. Os modos de viver a reabilitação, a disponibilidade e as condições de acesso dos trabalhadores que se vincularam a esta proposta foram os elementos que definiram, de certa forma, a participação de trabalhadores no grupo. Por condições de acesso entendemos as condições físicas para o deslocamento, compatibilidade de horário, disponibilidade para o trabalho grupal e motivação para discutir a temática da reabilitação profissional. Dos 18 trabalhadores que compareceram ao primeiro encontro, 11 iniciaram o grupo por concordarem com a proposta.

As manifestações dos trabalhadores no grupo, inicialmente, relacionaram-se à história de adoecimento, ao momento atual da vida profissional de cada um e às expectativas em relação ao fato de estarem sendo convidados por uma técnica do hospital (já que a pesquisadora é psicóloga da equipe de reabilitação) para integrar este grupo. Este fato provocou um sentido de "esperança" de que a empresa os estivesse acolhendo novamente para o trabalho, ainda que com suas restrições, ou que a pesquisadora pudesse ser portadora de alguma notícia nesse sentido.

Os primeiros encontros foram marcados por entradas e saídas do grupo, desistências que se anunciaram, desistências que se efetivaram, saídas e entradas na reabilitação, estas marcadas por intercorrências médicas, férias, presenças e faltas ao grupo. Esses movimentos grupais foram analisados coletivamente, legitimando o espaço grupal tanto para a pesquisadora, quanto para os trabalhadores e configurando o pertencimento ao grupo, o qual contou finalmente com a presença constante de sete participantes.

O processo grupal produziu uma retomada das histórias de trabalho no hospital, analisando os modos como os trabalhadores colocavam-se nas relações de trabalho e as marcas deixadas pelas práticas do cotidiano hospitalar. Também foi possível refletir e construir sentidos sobre trabalhar com a dor alheia (dos pacientes que atendiam) e as repercussões desse ofício para seus modos de viver, seus valores e práticas profissionais. Aos poucos, foram podendo dizer quais impactos o afastamento causava nas suas trajetórias e histórias de vida, trazendo as vivências de dor e de sofrimento pelo rompimento. A trajetória de adoecimento, a passagem do lugar de trabalhador do hospital para o de "doente" e os modos de lidar com suas limitações foram problematizados na medida em que foi possível analisar as estratégias utilizadas no percurso de trabalhador doente em benefício e em processo de reabilitação. Os efeitos do processo grupal e a revisão do contrato de trabalho foram temas recorrentes e que demarcaram os mergulhos do grupo em territórios ainda não explorados coletivamente.

As intervenções da pesquisadora fizeram-se a partir da escuta e da análise das estratégias utilizadas pelos trabalhadores em seus percursos e trajetórias no programa de reabilitação, apontando para os diferentes fluxos nos modos de viver e trabalhar.

A análise do corpus da pesquisa produzido (a transcrição das falas no grupo e o diário de campo do trabalho de pesquisa) teve como referência os pressupostos da genealogia proposta por Foucault (1988, 1998, 2003), buscando os movimentos de fixidez e descontinuidade presentes nas vivências dos trabalhadores em relação ao adoecimento como 
ruptura/acontecimento. Enfocou-se na análise os aspectos ligados às condições de possibilidade de enfrentamento das situações que o adoecimento (e a conseqüente reabilitação profissional) impõe, de modo a pensar os modos como as lutas de poder no contexto de trabalho podem definir esses movimentos como mais ou menos flexíveis.

A genealogia dos modos como os trabalhadores vivenciam o afastamento por adoecimento e a reabilitação profissional aponta para uma trama, tecida por múltiplos fios e atravessada pela singularidade da trajetória de cada trabalhador. A prática coletiva foi de buscar compreender a atualidade do material trazido pelo grupo, situando e elaborando coletivamente hipóteses sobre os modos como as experiências foram construindo-se particularmente. A trama é mostrada pelas vivências de espera e de dependência em relação à empresa ou à seguridade, pelo sofrimento decorrente das suas limitações para o trabalho e pela sensação de inutilidade, assim como pelas amarras colocadas pelas trajetórias profissionais no cenário capitalista contemporâneo. Cenário este, atualizado por histórias de trabalho, as quais são perpassadas por práticas que buscavam o reconhecimento pela via da produtividade e da disponibilidade ímpar em dar conta das demandas da empresa.

Num diálogo entre trabalhadoras ${ }^{7}$, escutamos:

Joana: Estou parada, esperando que eles me dêem uma colocação, conforme a minha condição, a minha escolaridade, o que eu conseguir fazer no quadro que eu estou. Tenho a oferecer dedicação pra aprender.

Simone: Achei que o hospital tinha esquecido de mim, eles não sabem nada de mim, não estão preocupados comigo como eu com eles. Um ano e quatro meses sem me ligar...

Ester: Quando a gente volta assim, se torna dependente dos próprios colegas da gente, e aí eles têm os trabalhos deles como é que tu vai pedir [ajuda]...

Simone: Não gosto de admitir isso, o hospital te coordena: "se o hospital... se eu não tiver consulta... se o hospital. Me chamar...".

A reabilitação profissional foi repensada na medida em que os jogos do trabalho ficavam evidentes. No grupo, ao se falar sobre as possibilidades de retorno ao trabalho, ou mesmo da permanência em benefício, tornavam-se visíveis tensionamentos, pontos de rigidez e movimentos de resistência (na perspectiva foucaultiana) das trajetórias de cada um e, dessa forma, o coletivo refletia sobre as construções políticas e sociais a respeito do trabalho e da reabilitação profissional. $\mathrm{O}$ envolvimento dos sete participantes no processo grupal era intenso: comunicavam suas ausências, retomavam questões pendentes de encontros anteriores, preocupavam-se uns com os outros e com o andamento do processo de pesquisa.

A trajetória desse grupo permitiu algumas constatações. A primeira delas é que, ao sairem da cadeia produtiva, os trabalhadores afastam-se de um lugar conquistado no processo de trabalho e de um lugar habitado enquanto sujeitos trabalhadores. $O$ rompimento imposto pelo adoecimento ameaçava um lugar social por eles conquistado via trabalho. Os

7 Joana, 35 anos, atendente de alimentação, trabalha desde 1997 na área de distribuição de refeições aos pacientes do hospital. Afastou-se do trabalho por problemas osteomusculares. Já tentou retornar para a área de origem com restrições, mas piorou seu quadro clínico, retornando para o auxílio doença. Tem restrições quanto a esforços físicos com membros superiores. Teve recente encaminhamento para retorno, mas não se sentiu em condições. Foi re-encaminhada ao INSS e teve alta. Pediu demissão do hospital por não se sentir em condições de retornar ao trabalho na área de origem, conforme indicado pela empresa por ocasião de alta médica. Simone, 36 anos, auxiliar administrativo no ambulatório do hospital há 13 anos. Afastada por problemas osteomusculares esteve em benefício por mais de um ano. Suas restrições são quanto ao esforço físico com os membros superiores e movimentos repetitivos. Faz faculdade de psicologia. Está em processo de reabilitação. Faz referência às estratégias que utiliza para lidar com sua situação. Ester, 45 anos, técnica de enfermagem trabalhou no centro de tratamento intensivo do hospital durante 16 anos. Afastou-se do trabalho por problemas osteomusculares e por acidente de trabalho. Sua história de trabalho é marcada por uma trajetória na qual buscou sempre seu aperfeiçoamento e locais de trabalho que a desafiassem. Relata ter resistido muito para aceitar seu adoecimento, fato que protelou etapas do tratamento clínico especializado que está tendo que retomar agora. Ainda está se recuperando de uma cirurgia recente, mas é provável que ela não possa mais retornar à atividade de enfermagem devido à gravidade da sua situação e das limitações decorrentes. 
trabalhadores sentem-se também ameaçados em relação ao poder aquisitivo, às relações sociais, ao convívio com colegas e ao lugar ocupado na família.

Esses trabalhadores são invadidos por um sentimento de que falharam, de que não podem acompanhar e manterem no jogo. Esse sentimento nutre-se de uma "fragilidade" construída a partir de uma percepção de inferioridade em relação a seus pares, por não poderem mais dar conta da sua atividade ou pelas inúmeras restrições para o seu cumprimento. Eles ocupam socialmente uma situação diferente e desigual. Essa posição produz o medo de serem rejeitados e excluídos pelo grupo, pela instituição e nas relações familiares e de convívio social. Ester nos conta:

No meu setor não tem lugar para mim, o que eu fui esses dezesseis anos no hospital não serve para mais nada, pra gente assimilar isso na hora não é bem assim, momento mais difícil para mim, eu não sou exceção de nada em lugar nenhum, isso é a realidade numa empresa, nós não somos únicas e nem insubstituiveis, e se os colegas tivessem me ajudado, é difícil aceitar, tu tinha um sonho de fazer uma coisa de crescer de conhecer de saber mais, de repente interrompeu.

O processo de reabilitação produz um "entre-lugar/não-lugar", pois existe a idéia de um presente incapaz e de um futuro incerto, que aponta para outra atividade ou para a mesma com restrições. Esse entre-lugar/não-lugar caracteriza-se pela lógica do regramento das organizações de trabalho capitalista, no qual há pouco espaço para manifestações diferentes daquelas já prescritas (com exceção da lei que prevê vagas para portadores de necessidades especiais). $\mathrm{Na}$ prática, a abertura de um espaço alternativo para o retorno dos trabalhadores da reabilitação só é possível garantindo-se a manutenção da produtividade, o que, nos casos dos trabalhadores com algum tipo de restrição, não pode ser garantido. Em alguns casos, até mesmo já se sabe de antemão que o espaço não é viável, pois suas limitações e restrições dificultam que desenvolvam as atividades exigidas ali. É importante ressaltar que é sempre o trabalhador que é colocado em questão e raramente o posto de trabalho no qual se originou o adoecimento é modificado, como é possível observar na fala que segue:

Joana: O que o hospital me oferecer que não prejudique a minha saúde eu vou aceitar, mas deixei a minha saúde em primeiro plano, deixei de lado essa coisa de escolher. Daí vai ser fácil já sei esse sistema de aprender a gostar das coisas. Tem mais oportunidade dai. Encaixe no serviço já é difícil, por causa das restrições.

As práticas do programa de reabilitação, ao adaptarem-se à organização do trabalho vigente, sem questionar seus efeitos, podem tornar o trabalhador uma peça a ser recolocada numa engrenagem, à qual ele deverá adequar-se.

Os trabalhadores que adoecem vivenciam esse rompimento tendo em conta também seus estilos de vida. Os modos de se reconhecerem nas relações consigo e com os outros estão pautados por um código moral sustentado na idéia de trabalho assalariado. A centralidade do trabalho é um fator importante no estabelecimento dos modos de viver e, assim, o afastamento do trabalho desestabiliza os trabalhadores, trazendo sofrimento. No entanto, o rompimento também poderia, ao desestabilizar, produzir alternativas e modos de trabalhar diferenciados, talvez mais "saudáveis" e inventivos, mas raramente esse movimento é possível se o afastamento é vivido de forma solitária. Num diálogo entre trabalhadoras:

Simone: Não posso limpar a minha casa direto, durante a semana faço um pouquinho e final de semana tá tudo limpinho, tenho aquelas mesinha de rodinha na cozinha e dia de faxina, boto o balde ali e dai não preciso estar buscando ele, me adapto.

Joana: A gente quer progredir, é um regredimento quando a gente tá doente e não tá trabalhando. 
A situação de afastamento do trabalho impõe uma revisão dos modos de vida desses trabalhadores, desestabiliza, movimenta, tensiona e exige recursos para a busca ou a produção de linhas de fuga. Mas percebe-se que, muitas vezes, o desejo já cedeu o seu espaço para as rotinas, cadências e planilhas. Os corpos podem mostrar-se dóceis e enfatizarem o reconhecimento dentro do já prescrito.

O afastamento pelo adoecimento é vivenciado como rompimento com o trabalho através do corpo: invertendo a lógica ou potencializando-a no sentido de que o corpo do trabalho invade o corpo do trabalhador até o ponto da insustentabilidade da situação. E, no momento do adoecimento, o corpo do trabalhador dilui-se no corpo do trabalho e eles não mais se diferenciam - o corpo do trabalhador é só trabalho -, até o adoecimento e a incapacidade. No caso do adoecimento pelo trabalho, o corpo pode deixar de ser corpo múltiplo e diversificado do trabalhador, pois é dor e sofrimento, e o trabalho deixa de ser trabalho com potencialidade de criação e de produção, pois é restrição, impotência e limitação. Onde estava posto que corpo é potência e trabalho é produção (marcas do capitalismo), coloca-se: corpo como impotência e trabalho como improdutividade (ou impossibilidade). Nesse caso, configura-se uma relação que se automatiza através de uma imbricação e de um encadeamento entre corpo e trabalho, sendo que se implicam e afetam-se mutuamente a ponto de (com)fundirem-se: efeito da disciplinarização dos corpos e do controle dos ritmos e cadências, conforme analisados por Foucault (1991). Em um diálogo entre as trabalhadoras, escutamos:

Ester: São coisinhas, mas que para nós é muito importante, a gente começa a ampliar a visão, parece que um véu se abre, uma coisa é tu tá em pé do lado de uma cama com uniforme. Outra coisa é tu estar deitada. Fica vinte e quatro horas com as luzes ligadas para ti ver! Barulho na unidade de noite.

Simone: Se tu não leva um pontapé, tu não vence. Que bom que levei um pontapé. Cada dificuldade para mim é uma oportunidade. Pude me conhecer me descobri, como eu sou chata dentro de casa, eu não sabia o que eu queria, agora eu sei, e eu não posso. Eu posso fazer tudo, mas eu não devo.

Joana: Automaticamente a gente se obriga a parar. Começa a pensar: como é que eu trabalhava, por que eu não fazia com calma. É um tempo que tu tem pra te analisar, pra vê o que tu tava fazendo de errado, começa a ter esse cuidado agora com a minha saúde, não fazer esforço, foi até bom, é uma experiência que a gente tem na vida, é um conhecimento a mais. Só pensava em produzir, agora vou ter outro pensamento, tenho os meus limites.

O rompimento pelo adoecimento traz a necessidade de aprender a conviver com a dor, a dor física e a dor psicológica, aqui diferenciadas para melhor caracterizar o sofrimento relacionado: ora a dor física referente à patologia, ora a dor psicológica ligada ao rompimento, ao "não posso mais", ao sentir-se inútil e, ao mesmo tempo, à acusação de "simulação" (os trabalhadores sentem-se discriminados nas perícias e consultas, pelos colegas e chefias, pelos familiares e amigos). Esse assujeitamento, nomeado como "aprendizagem", muitas vezes vê-se perpassado por uma vivência de resignação, demonstrando a sutileza dos pontos no quais se fixa. Exemplo disso é uma situação trazida no grupo por uma trabalhadora que conviveu dez anos com uma dor de dente, dor que está ali, no corpo, na superfície da latência, tão presente como obscura, pulsando, como ponto de resistência de uma dor que não se esquece.

O rompimento com o trabalho, enquanto um acontecimento (Carreteiro, 2003), provoca uma revisão. Revisão dos modos de viver, dos sentidos do trabalho (Tittoni, 1994), das práticas de trabalho e das relações com o trabalho. Os modos de sujeição, o poder da norma e seus efeitos podem ser visibilizados por essa revisão, disparada pela experiência de rompimento. Pode-se pensar nos efeitos da experiência da reabilitação profissional através do exercício de repensar os modos de trabalhar que foram vivenciados pelo grupo em questão. 
É através da forma como o trabalho toma o corpo que as dificuldades para o retorno concretizam-se, em outras palavras, as manifestações sobre as possibilidades de retornar, ou não, ao trabalho aparecem referenciadas pela possibilidade de os trabalhadores lidarem ou não com as suas dores e limitações físicas.

Os trabalhadores, ao falarem do que não podem, conseguem dizer da possibilidade de não retorno ao trabalho, das dificuldades, receios, resistências, vantagens e desvantagens em relação ao retorno. Estes aparecem referenciados no corpo e no impacto do trabalho sobre ele, mostrando, ao mesmo tempo, a face da produtividade e da inutilidade.

O movimento de questionar as práticas de trabalho anteriormente experimentadas é permeado pela vivência da inutilidade. Isso evidencia um ponto de tensão no qual os regimes de verdade do trabalho são tomados como referências para a experiência de si e para o autoreconhecimento.

A mesma relação de trabalho que subordina, no entanto, pode mostrar vias de rompimento com o regramento social, na busca de um posicionamento ético de busca da alteridade. A violência decorrente do afastamento do trabalho por adoecimento pode ser o disparador desse processo.

\begin{abstract}
Simone: Essas aulas têm mudado alguma coisa em vocês? Tô perguntando isso porque eu tô pensando: essa idéia de que a gente é dependente do trabalho não é só da gente, é da sociedade! Coloquei isso em casa e me chamaram de louca, eu nunca tinha pensado nisso, nunca tinha pensado nisso, ou eu paro de trabalhar aqui no hospital, ou eu mudo de faculdade, serviço social, sociologia, certamente não seria o que eu quero [na faculdade de psicologia que cursa, as aulas são diurnas, assim sendo, seu retorno ao trabalho, impediria que continuasse o curso]. Antes dos grupos eu pensava em outras alternativas, não sei quais, tô com esse dilema por causa destas aulas...
\end{abstract}

Carreteiro (2003) conclui que os acontecimentos colocam em questão, nos percursos de vida, as dimensões pessoais, familiares, sociais e históricas. Deve-se, portanto, considerar, para a sua elaboração, não somente a capacidade do sujeito, mas também as "condições de acolhimento" presentes no contexto. Carreteiro (2003) define acolhimento como as condições de suporte, presentes no contexto, que funcionam como apoio. Para a autora, "o acolhimento, pode funcionar como uma espécie de envelope de proteção que, ao mesmo tempo que fornece um holding (na perspectiva de Winnicott), não cria uma limitação para o sujeito" (Carreteiro, 2003, p. 284).

A partir da revisão das experiências de trabalho que compreendem trajetória de adoecimento e afastamento, consideramos que o afastamento do trabalho em razão do adoecimento pode ser o disparador de um processo de ressignificação. Nesse sentido, pensamos que a experiência da reabilitação talvez possa, para além de uma recolocação no mercado de trabalho, ser vivenciada enquanto inflexão consigo e de um devir outro. Consideramos a potencialidade de "...um lado de dentro da vida, do trabalho e da linguagem, no qual o homem se aloja, ainda que para dormir, mas, inversamente também, que se aloja no homem em vigília enquanto ser vivo, indivíduo no trabalho ou sujeito falante" (Deleuze, 1988, p. 104).

\title{
Algumas considerações, para finalizar...
}

A experiência desses trabalhadores mostra-nos, sobretudo, a potência da dimensão do trabalho na análise dos processos de subjetivação contemporâneos. Os trabalhadores compartilharam, em movimentos gerados pela experiência do grupo, o entendimento de que o fato de estarem "fora" do trabalho deve-se a fatores que não dependem, necessariamente, do 
empenho ou da vontade individuais. Por vezes, o adoecimento está relacionado a formas de organização do trabalho impostas, ritmos acelerados e intensos, de difícil controle por parte dos trabalhadores. No afastamento do trabalho por adoecimento profissional, as questões da organização e das condições de trabalho estão em destaque, pois o adoecimento origina-se do trabalho. Nessas situações, o "fora" do trabalho, ao mesmo tempo em que evidencia a possibilidade da saúde (pois o trabalhador se afasta da fonte de adoecimento), também marca o sujeito com a incapacidade e a fragilidade, pois a lógica do "retorno" ao trabalho está orientada para a mesma função ou atividade que originou o adoecimento.

As experiências desses trabalhadores apontaram para os jogos de poder e verdade presentes na reabilitação. A verdade que concebe o adoecimento como individualizado, gera o sentimento de inutilidade, pois é necessário admitir as limitações e aceitar adaptar-se ao que não se pode, resignando-se, muitas vezes, ao que é oferecido pela empresa. Tal sentimento de inutilidade reporta aos modos como, no decorrer de sua trajetória profissional, os trabalhadores foram se reconhecendo, aos modos como compreendem o que é ser trabalhador. As relações de trabalho, como modos de sujeição, concorreram para a legitimação de um lugar de trabalhador de que agora não podem mais dar conta.

O retorno ao trabalho, muitas vezes o retornar "àquele" trabalho, constitui-se em importante objetivo de suas vidas e na forma de refazer a imagem (ou a identidade) de um "bom" trabalhador, reconhecido pela sua capacidade produtiva. As histórias de trabalhadores que seguem buscando qualificações, em áreas onde não poderão trabalhar em razão do adoecimento, demonstram o desejo de "refazer" a imagem "quebrada" pelo adoecimento. A busca do emprego como locus privilegiado da produção do "bom" trabalhador também demonstra a potência dessa identidade, pois "bom trabalhador" é aquele que consegue emprego.

A associação do emprego ao trabalho-produção, apesar de configurar-se de diferentes formas na sociedade contemporânea, ainda é bastante forte. É na estrutura formal do emprego que o trabalhador é legitimado, que se reconhece e é reconhecido socialmente. O emprego, apesar das evidências contrárias, ainda é o "lugar" do trabalho ideal.

O afastamento do trabalho fratura uma relação construída, na qual o trabalhador atende o chamamento das demandas do trabalho, sente-se satisfeito por poder atendê-las, espera o reconhecimento do outro e, a partir dele, investe novamente.

Se pensarmos a lógica do trabalho capitalista, pode-se dizer que ocorre um processo de "sucateamento" do trabalhador quando as práticas de reabilitação recolocam o trabalhador nas mesmas atividades exercidas antes do adoecimento, ainda que "com restrições" ou mantendo-o "na geladeira" (afastamentos que se prolongam durante meses ou até mesmo anos). A vinculação à seguridade parece estar mais focada nos modos de trabalhar que produziram o adoecimento, deixando de estimular, ou mesmo oferecer aos trabalhadores, alternativas diferentes de trabalho e de produção. Há um culto do "retorno ao antigo posto de trabalho", mesmo sabendo que o lugar a ser ocupado pelo trabalhador reabilitado possa ser o de exceção, marcado pelas limitações. A prática do retorno ao trabalho com restrições, ou mesmo da aposentadoria por invalidez, também é um modo de individualização do adoecimento e de culpabilização do trabalhador. Dessa maneira, resolvem-se os casos de maneira pontual e individual sem estudar e propor mudanças nos ambientes, na organização e nas práticas de trabalho que possam estar sendo lesivas aos trabalhadores. As práticas de reabilitação, dessa forma, também marcam a incapacidade e a quase "inutilidade" dos trabalhadores, nas quais a vergonha e a culpa são as faces mais evidentes dessas estratégias de dominação.

Constata-se que a perspectiva mais comum das práticas em reabilitação profissional, ao configurar uma lógica assistencialista, sujeita o trabalhador, reiterando a relação de dependência até então experienciada no trabalho. Essa lógica, ao privilegiar a incapacidade do corpo do trabalhador, manifesta o maniqueísmo com que o capital tem tomado os sujeitos 
como instrumento para atingir seus objetivos, quais sejam: produtividade, lucro e acumulação de riqueza.

Entendemos essas práticas como jogos de poder que, em seus pontos de tensão, também apresentam movimentos de ruptura que podem apontar para a visibilização de outras identidades possíveis (neste caso, legitimadas nas reflexões coletivas que marcaram a dinâmica dos encontros do grupo). Na trajetória do grupo estudado, também as experiências de transgressão da lógica dos jogos de verdade mostraram-se eficientes e singulares como ruptura/acontecimento e como possibilidade de afirmação de um movimento de resistência. A lógica da produção e as práticas divisórias mostram-se mais potentes que a capacidade de resistência, mas mesmo assim o movimento dos trabalhadores no grupo mostrou que, apesar desse contexto de adversidades, eles buscam encontrar novas formas de viver. A partir da problematização dos modos de experimentar a reabilitação, alguns modos de trabalhar foram sendo visibilizados, bem como suas estratégias para lidar com o regramento e seus jogos de poder e de verdade. Isso possibilitou que, em grupo, as estratégias para lidar com a reabilitação fossem discutidas e os movimentos de resistência e ruptura fossem sendo evidenciados na forma dos modos de viver a reabilitação profissional, ora como "encosto" e acomodação, ora como punição e sofrimento, ora como possibilidade de revisão dos modos de trabalhar e como impulso para a busca de outros modos de viver. No entanto, a busca de novas formas de viver esbarra na captura identitária, que fixou um único lugar de trabalhador na configuração dos jogos de poder capitalistas. Na medida em que tais capturas fundamentam-se em um "ideal", o trabalhador afastado subjetiva-se como "incapaz" ou mesmo "deficitário", buscando dar conta dessa imagem idealizada de um trabalho (e até mesmo de um trabalhador) quase perfeito.

Ao compararmos nosso estudo atual com pesquisas anteriores com trabalhadores afastados do trabalho por adoecimento profissional em atendimento no Ambulatório de Doenças Profissionais do Hospital de Clínicas de Porto Alegre e no serviço de saúde do Sindicato da Indústria Química e Petroquímica de Triunfo (Sindipolo), em 1993 (Tittoni, 1999), constatamos uma importante semelhança entre essas diferentes experiências. Apesar dos doze anos que separam tais estudos, os semelhantes sentimentos de incapacidade, fragilidade e insegurança trazidos pelo afastamento do trabalho visibilizam uma regularidade que pressiona para o lugar destinado a esses trabalhadores na sociedade. A regularidade da descartabilidade e do descaso com o trabalhador adoecido expressa-se tanto na manutenção da via-crucis institucional-legal, quanto nas formas e estratégias de reinserção dos trabalhadores no mercado de trabalho, reafirmando a potência da rede enunciativa que sustenta a verdade do sucesso no capitalismo, a partir da hipervalorização da produtividade, da eficiência, da perfeição e da qualidade. Assim, aqueles que não podem mais dar conta dessa convocação ficam, conforme afirma Castel (1998), "fora" dela, a perfilar-se no mundo dos "desfiliados" e "supranumerários", a convocar-nos, enquanto estudiosos, para uma "nova questão social".

\section{Referências}

Barreto, M. M. S. (2004). Violência, saúde, trabalho: uma jornada de humilhações. São Paulo: Educ.

Barros, R. B. (1997). Dispositivos em ação: o grupo. In A. E. Silva et al. (Orgs.), Subjetividade: questões contemporâneas (Saúde e Loucura, vol. 6, pp. 183-191). São Paulo: Hucitec.

Barros, R. B. (1994). Grupo: afirmação de um simulacro. Tese de Doutorado, Programa de Pós-Graduação em Psicologia Clínica, Faculdade de Psicologia, Pontifícia Universidade Católica de São Paulo, São Paulo.

Barros, R. B. (2007). Grupo: a afirmação de um simulacro. Porto Alegre: Sulina/UFRGS.

Canguilhem, G. (2002). O normal e o patológico (5aㅡ ed.). Rio de Janeiro: Forense Universitária. 
Carreteiro, T. C. (2003). Acontecimento: categoria biográfica individual, familiar, social e histórica. In T. FéresCarneiro (Org.), Família e casal: arranjos e demandas contemporâneas (pp. 267-285). Rio de Janeiro: PUCRio. São Paulo: Loyola.

Castel, R. (1998). As metamorfoses da questão social: uma crônica do salário. Petrópolis: Vozes.

Deleuze, G. (1988). Foucault. São Paulo: Brasiliense.

Foucault, M. (1991). Vigiar e punir: história da violência nas prisões (8ª ed.). Petrópolis: Vozes.

Foucault, M. (1995). O sujeito e o poder. In H. L. Dreyfus \& P. Rabinow (Orgs.), Michel Foucault: uma trajetória filosófica para além do estruturalismo e da hermenêutica (pp. 231 -249). Rio de Janeiro: Forense Universitária.

Foucault, M. (1988). História da sexualidade 1: a vontade de saber. Rio de Janeiro: Graal.

Foucault, M. (1998). História da sexualidade 2: o uso dos prazeres. Rio de Janeiro: Graal.

Foucault, M. (1999). Estética, ética y hermenêutica (vol. 3). Barcelona: Paidós.

Foucault, M. (2003). O nascimento do Hospital. In Microfísica do poder (18ª ed., pp. 99-111). Rio de Janeiro: Graal.

Nardi, H. C. (2003). A propriedade social como suporte da existência: a crise do individualismo moderno e os modos de subjetivação contemporâneos. Psicologia $\mathcal{E}$ Sociedade, 15 (1), 37-56.

Nardi, H. C. (1999). Saúde, trabalho e discurso médico: a relação médico-paciente e o conflito capital-trabalho. São Leopoldo: Unisinos.

Ortega, F. (1999). Amizade e estética da existência em Foucault. Rio de Janeiro: Graal.

Ramos, M. Z. (2005). Trabalho, subjetividade e reabilitação profissional: por uma genealogia dos modos de vida. Dissertação de Mestrado, Programa de Pós-Graduação em Psicologia Social e Institucional, Universidade Federal do Rio Grande do Sul, Porto Alegre.

Rocha, M. L., \& Aguiar, K. F. (2003). Pesquisa-intervenção e a produção de novas análises. Psicologia Ciência e Profissão, 203 (4), 64-73.

Tittoni, J. (1994). Subjetividade e trabalho. Porto Alegre: Ortiz.

Tittoni, J., \& Nardi, H. C. (1995). Relações saber/poder na discussão sobre subjetividade e trabalho. Cadernos de Sociologia, Porto Alegre, 7, 151-167.

Tittoni, J. (1999). Trabalho e sujeição: trajetórias e experiências de trabalhadores demitidos no setor petroquímico. Tese de Doutorado, Programa de Pós-Graduação em Sociologia, Universidade Federal do Rio Grande do Sul, Porto Alegre.

Tittoni, J. (2008). Trabalho, poder e sujeição: trajetórias entre o emprego, o desemprego e os "novos" modos de trabalhar. Porto Alegre: Dom Quixote.

\section{Endereço para correspondência}

mzramos@cpovo.net, jaquemin@terra.com.br,hcnardi@terra.com.br

Recebido em: 03/03/2008

Revisado em: 28/07/2008

Aprovado em: 13/08/2008 